\title{
Squamous cell carcinomas of the esophagus arise from a telomere-shortened epithelial field
}

\author{
MAKOTO KAMMORI ${ }^{1,2}$, STEVEN S.S. POON ${ }^{3}$, KEN-ICHI NAKAMURA ${ }^{2}$, NAOTAKA IZUMIYAMA ${ }^{2}$, \\ NAOSHI ISHIKAWA ${ }^{2}$, MASAHIKO KOBAYASHI $^{4}$, YOSHIO NAOMOTO $^{4}$ and KAIYO TAKUBO ${ }^{2}$ \\ ${ }^{1}$ Division of Breast and Endocrine Surgery, Department of Surgery, Nihon University School of Medicine, Tokyo; \\ ${ }^{2}$ Research Team for Geriatric Disease, Tokyo Metropolitan Institute of Gerontology, Tokyo, Japan; \\ ${ }^{3}$ Terry Fox Laboratory, British Columbia Cancer Research Center, Vancouver, BC, Canada; \\ ${ }^{4}$ Division of Gastrointestinal Surgery, Department of Surgery, Graduate School \\ of Medicine, Okayama University, Okayama, Japan
}

Received August 3, 2007; Accepted September 10, 2007

\begin{abstract}
Critically shortened telomeres make chromosomes susceptible to the instability and widespread cytogenetic alterations that characterize most human cancers. We hypothesized that the very rapid cell proliferation observed in esophageal squamous cell carcinomas might accelerate telomere shortening and chromosomal instability associated with carcinogenesis. We used a number of telomere measurement techniques including quantitative fluorescence in situ hybridization (Q-FISH) to compare chromosomal aberrations and telomere lengths of individual chromosomes in esophageal squamous cell carcinomas (ESCCs) and nearby nonneoplastic esophageal epithelium (NNEE) cells. Our results showed that the mean telomere length in ESCC cells was significantly less than that in adjacent NNEE cells, and that telomeres in all NNEE cells were significantly shorter than those in normal esophageal epithelium (reported previously). In addition, there was no evidence linking telomere shortening of a particular chromosome to field cancerization in ESCC. However, a mechanistic link between telomere shortening and chromosomal instability was supported by a higher frequency of anaphase/telophase bridges and an increase in the frequency of aneuploidy. This study furthers our
\end{abstract}

Correspondence to: Dr Makoto Kammori, Division of Breast and Endocrine Surgery, Department of Surgery, Nihon University School of Medicine, 30-1 Oyaguchi Kami-machi, Itabashi-ku, Tokyo 173-8610, Japan

E-mail: kanmori-dis@umin.ac.jp

Abbreviations: ESCC, esophageal squamous cell carcinoma; NNEE, non-neoplastic esophageal epithelium; Q-FISH, quantitative fluorescence in situ hybridization; IHC, immunohistochemistry

Key words: telomere shortening, chromosome instability, esophageal squamous cell carcinoma, non-neoplastic esophageal epithelium, esophagus, quantitative fluorescence in situ hybridization, anaphase/telophase bridges, carcinogenesis, field cancerization understanding of the mechanism by which telomere shortening and chromosomal instability lead to carcinogenesis and field cancerization in the esophagus.

\section{Introduction}

Telomeres are nucleoprotein complexes located at the ends of eukaryotic chromosomes, and play an important role in the maintenance of genomic integrity. Telomeres cap the ends of human chromosomes, protecting them against chromosome fusion and preventing the chromosome termini from being recognized as double-stranded DNA breaks (1-5). Because conventional DNA replication cannot completely replicate the ends of linear chromosomes, normal somatic cells lose telomeric repeats with each cell division, both in vivo and in vitro; a phenomenon referred to as the 'end-replication problem'. Human telomeres thus play critical roles in the maintenance of chromosomal stability as well as in limiting the ultimate replication capacity of cells. Telomere shortening has been proposed to be an important biological factor in carcinogenesis, cell senescence, cell replication, cell immortality, and aging (6-10). To further understand the relationship between telomere metabolism and field cancerization in esophageal squamous cell carcinomas (ESCCs) and nearby non-neoplastic esophageal epithelium (NNEE), it is important to measure and compare the telomere lengths of these two regions.

In a previous study, we investigated age-related shortening of telomere lengths in normal esophageal tissues and derived a slope (-60 bp per year) for the linear regression line on the basis of Southern blot data (11). We hypothesized that the very rapid cell proliferation that occurred in ESCC might accelerate the telomere loss in this region as compared with the nearby NNEE region. In the present study, we used a number of different techniques to test this hypothesis. First, we employed quantitative fluorescence in situ hybridization (Q-FISH) to measure the telomere lengths of individual chromosomes in metaphases from samples derived from the two cell populations. Second, we examined aneuploidy by observing the expression of subtelomeres and centromeres in 
ESCC and NNEE cells using multi-color fluorescence in situ hybridization (FISH). Third, we quantified chromosomal instability by counting the frequency of anaphase/telophase bridges between ESCC and NNEE cells. Finally, we measured the telomere lengths of normal esophageal tissues from autopsy samples using traditional Southern blotting techniques and compared the results with those (Q-FISH) of the NNEE and ESCC cells.

\section{Materials and methods}

Sources of cells used for primary cell cultures. Specimens of esophageal carcinoma and adjacent normal tissue were obtained from 15 patients who underwent esophageal resection at Tokyo Metropolitan Geriatric Hospital, Tokyo, and Okayama University Hospital, Okayama, Japan. We used the standard criteria for histological grading (12) of the collected specimens. Samples from these specimens were then used to produce primary cell cultures. These studies were performed with approval from the Tokyo Metropolitan Institute of Gerontology and Okayama University Institutional Human Subjects Review Board and with the informed consent of all participating subjects.

From among the 15 patients, we established both ESCC (number of chromosomes, 67 or 68) and NNEE (number of chromosomes, $46 \mathrm{XY}$ ) cells from two patients and only NNEE cells from six other patients. NNEE cells were grown in $25-\mathrm{cm}^{2}$ plastic tissue culture flasks (Falcon; Becton Dickinson Co., Franklin Lakes, NJ) in a humidified incubator $\left(37^{\circ} \mathrm{C}, 84 \%\right.$ humidity, 5\% $\mathrm{CO}_{2}$ /ambient air atmosphere) in KeratinocyteSFM medium (KSFM) (Invitrogen Corp., Carlsbad, CA) supplemented with $40 \mu \mathrm{g} / \mathrm{ml}$ bovine pituitary extract (BPE) (Kurabo, Kobe, Japan), $1.0 \mathrm{ng} / \mathrm{ml}$ epidermal growth factor (EGF) (Invitrogen Corp.), $100 \mathrm{U} / \mathrm{ml}$ penicillin, and $100 \mu \mathrm{g} /$ $\mathrm{ml}$ streptomycin (Invitrogen Corp.). ESCC cells were grown in $25-\mathrm{cm}^{2}$ plastic tissue culture flasks in a humidified incubator $\left(37^{\circ} \mathrm{C}, 84 \%\right.$ humidity, $5 \% \mathrm{CO}_{2} /$ ambient air atmosphere) in RPMI-1640 medium (Sigma Co., NY) supplemented with 10\% FCS (Moregate BioTech, Australia and New Zealand), $100 \mathrm{U} / \mathrm{ml}$ penicillin, and $100 \mu \mathrm{g} / \mathrm{ml}$ streptomycin (Invitrogen Co.). The NNEE and ESCC cells were passaged weekly at $75 \%$ confluence using $0.25 \%$ trypsin $/ 0.02 \%$ ethylenediaminetetraacetic acid (Life Technologies, Inc., Rockville, MD) for detachment, followed by inactivation with serum-containing media (normal or charcoal-stripped as appropriate) and by seeding into new flasks using a split ratio of 1:10. All cells were found to be free of mycoplasma contamination using a polymerase chain reaction-based mycoplasma detection kit obtained from the ATCC (catalog no. 90-1001K, Rockville, MD). All media and passaging procedures were carried out in accordance with the accompanying ATCC recommendations.

Metaphase preparations using quantitative fluorescence in situ hybridization (Q-FISH) and karyotype analysis. The esophageal cancer and epithelium cell cultures were treated with $0.1 \mu \mathrm{g} / \mathrm{ml}$ colcemid (Sigma Co.) for $30 \mathrm{~min}$ to accumulate mitotic cells, which were later harvested in accordance with the standard cytogenetic procedure. After hypotonic swelling in $\mathrm{KCl}$ buffer for $18 \mathrm{~min}$ at $37^{\circ} \mathrm{C}$, the cells were fixed by three washes with methanol/acetic acid (3:1), dropped onto clean wet slides, and dried overnight. In situ hybridization was performed with a telomere Cy3conjugated (CCCTAA) ${ }_{3}$ probe and a centromere FITCconjugated (CTTCGTTGGAAACGGGGT) peptide nucleic acid (PNA) probe (PBIO/Biosearch Products, Bedford, MA) as described previously (13-15). The chromosome preparations were counterstained with 4',6-diamidino-2-phenylindole (DAPI; Molecular Probes, Eugene, OR). For chromosomal analysis, the cells were karyotyped from Q-FISH samples (DAPI-stained chromosomes and FITC-stained centromeres) using the standard air-drying method (16). These cells were then treated with $0.1 \mu \mathrm{g} / \mathrm{ml}$ colcemid for $2 \mathrm{~h}$ during the nonexponential growth phase. The cells were analyzed using an ISIS Karyotyping System (Metasystem GmbH, Altlussheim, Germany) and trypsin G-banding. A count of the modal

Quantitative fluorescence in situ hybridization and image analysis of telomeres. Q-FISH and image analysis were performed as described previously (17). Digital images were recorded with a CCD camera, ORCA-ER-1394 (Hamamatsu Photonics KK, Hamamatsu, Japan) on a Nikon $80 \mathrm{i}$ epifluorescence microscope (Eclipse 80i FU-RFL, Nikon, Tokyo, Japan) equipped with a triple band-pass filter (61010, Chroma Technology, Corp., Rockingham, VT) and a x60 oil objective lens (Plan Apo 60x/1.4, Nikon, Tokyo, Japan) for Cy3/FITC/DAPI. Microscope control and image acquisition were both performed using Image-Pro Plus software (ver. 5.0, Media Cybernetics Co. Ltd., MD). Two levels of calibration were used to ensure a reliable quantitative estimation of telomere length in various samples. First, to correct for daily variations in lamp intensity and alignment, images of fluorescent beads (orange beads, size $0.2 \mu \mathrm{m}$, Molecular Probe Inc.) were acquired and analyzed using the same software that estimates telomere lengths of individual chromosomes (TFL-TELO, ver. 2.0, Terry Fox Laboratory, BC Cancer Research Center, Canada). Second, the conversion of telomere intensities to telomere fluorescence units (TFUs) was obtained experimentally by correlation with Southern blot data for our cell line TIG-1 (population doublings of 12, 32, 60, and 62) (data not shown).

Southern blotting. Southern blotting and data analysis were performed as described previously (11).

Sample preparation for FISH analysis of the subtelomeres. FISH analysis using the primary cultured cells was performed as described by Bosch et al (18). The slides were washed in a standard 2X SSC solution, dehydrated in an ethanol series, and denatured for 3-5 min in 70\% formamide solution at $73^{\circ} \mathrm{C}$. For the FISH analysis, the following multicolor TelVysion telomeric probes (Abbott Molecular Inc., IL) were used: $3 p, 6 p, 8 p, 9 p, 11 p$, and 12p (Spectrum Green); 3q, 6q, 8q, 9q, 11q and 12q (Spectrum Orange); 13p, $17 \mathrm{p}, 18 \mathrm{p}, 17 \mathrm{q}$, and $18 \mathrm{q}$ (Spectrum Green and Spectrum Orange, mix appears as yellow); and 13q, 14, 17, and 18 centromeres (Spectrum Aqua). The probes were denatured at $73^{\circ} \mathrm{C}$ for $5 \mathrm{~min}$, and then the slides were hybridized with probes in a dark chamber for $12-24 \mathrm{~h}$ at $37^{\circ} \mathrm{C}$. DAPI-III 
Table I. Mean fluorescence intensities (MFI) and lengths of telomeres in esophageal epithelial and cancer cells.

\begin{tabular}{|c|c|c|c|c|c|c|c|c|c|}
\hline $\begin{array}{l}\text { Sample } \\
\text { no. }\end{array}$ & $\begin{array}{c}\text { Age } \\
\text { (years) }\end{array}$ & Sex & $\begin{array}{l}\text { Metaphase } \\
\text { spreads } \\
\text { examined }\end{array}$ & $\begin{array}{c}\text { MFI of } \\
\text { telomeres on } \\
\text { p- and q-arms }\end{array}$ & $\begin{array}{c}\text { MFI of } \\
\text { telomeres } \\
\text { on p-arms }\end{array}$ & $\begin{array}{c}\text { MFI of } \\
\text { telomeres } \\
\text { on q-arms }\end{array}$ & $\begin{array}{c}\text { Mean } \\
\text { telomere } \\
\text { lengths }(\mathrm{kbp})^{\mathrm{a}}\end{array}$ & $\begin{array}{l}\text { Mean telomere } \\
\text { lengths of } \\
\text { p-arms (kbp) }\end{array}$ & $\begin{array}{c}\text { Mean telomere } \\
\text { lengths of } \\
\text { q-arms (kbp) }\end{array}$ \\
\hline E7N & 45 & M & 13 & $6396 \pm 5358$ & $6525 \pm 5475$ & $6268 \pm 5238$ & $7.8 \pm 4.0$ & $7.9 \pm 4.0$ & $7.7 \pm 3.9$ \\
\hline E8N & 58 & $\mathrm{M}$ & 11 & $3889 \pm 3007$ & $3753 \pm 2918$ & $4026 \pm 3088$ & $5.9 \pm 2.2$ & $5.8 \pm 2.2$ & $6.0 \pm 2.3$ \\
\hline E9N & 68 & M & 12 & $5358 \pm 4686$ & $5211 \pm 4511$ & $5505 \pm 4853$ & $7.0 \pm 3.5$ & $6.9 \pm 3.3$ & $7.1 \pm 3.6$ \\
\hline E9Ca & & & 12 & $\begin{array}{c}3692 \pm 2201 \\
(69 \% \text { of normal) }\end{array}$ & - & - & $5.7 \pm 1.7$ & - & - \\
\hline E10N & 58 & $\mathrm{M}$ & 13 & $4173 \pm 2917$ & $4046 \pm 2824$ & $4301 \pm 3003$ & $6.2 \pm 2.2$ & $6.1 \pm 2.1$ & $6.2 \pm 2.2$ \\
\hline $\mathrm{E} 10 \mathrm{Ca}$ & & & 11 & $\begin{array}{c}3120 \pm 1863 \\
\text { (75\% of normal) }\end{array}$ & - & - & $5.4 \pm 1.4$ & - & - \\
\hline E11N & 48 & M & 11 & $4867 \pm 3746$ & $4881 \pm 3802$ & $4853 \pm 3691$ & $6.7 \pm 2.8$ & $6.7 \pm 2.8$ & $6.7 \pm 2.7$ \\
\hline E12N & 74 & M & 10 & $3725 \pm 2263$ & $3715 \pm 2218$ & $3736 \pm 2307$ & $5.8 \pm 1.7$ & $5.8 \pm 17$ & $5.8 \pm 1.7$ \\
\hline E13N & 64 & M & 11 & $5609 \pm 4721$ & $5593 \pm 4797$ & $5626 \pm 4645$ & $7.2 \pm 3.5$ & $7.2 \pm 3.5$ & $7.2 \pm 3.4$ \\
\hline E14N & 68 & M & 11 & $8852 \pm 7249$ & $8838 \pm 7296$ & $8865 \pm 7206$ & $9.6 \pm 5.3$ & $9.6 \pm 5.4$ & $9.6 \pm 5.3$ \\
\hline
\end{tabular}

${ }^{\mathrm{a}}$ The mean telomere lengths of chromosomes in the ESCC cells were significantly less $(\mathrm{p}<0.0001)$ than those in the corresponding NNEE of the same patient.

counterstain (Abbott Molecular Inc.) and anti-fade were applied to the slides prior to observation. Cell nuclei decondensation was carried out by incubating the slides in a solution of $5 \mathrm{mM} \mathrm{DTT}$ at $37^{\circ} \mathrm{C}$ for $8-15 \mathrm{~min}$ before denaturation. For subtelomeric probes, slides were treated with pepsin and post-fixed with $1 \%$ formaldehyde solution prior to hybridization. Images were examined qualitatively using our epifluorescence microscope system Eclipse 80i FU-RFL.

Immunohistochemical staining analysis. IHC was performed using the avidin/biotin complex/horseradish peroxidase method (19). Tissue sections, 4- $\mu \mathrm{m}$ thick, were stained for hTERT with a monoclonal antibody (NCL-L-hTERT; Novocastra, Newcastle-upon-Tyne, UK).

Sample preparation for anaphase/telophase bridge analysis. The ESCC and NNEE cultures were fixed without colcemid treatment, stained for $30 \mathrm{sec}$, Giemsa stained, and analyzed using a light microscope. At least 1000 chromatin bridges were evaluated in each case.

Statistical analysis. Differences in p values were analyzed by the Chi-square test for independence, and Fisher's z test and Pearson's correlation coefficient were used to compare any correlations. In all comparisons, differences of $\mathrm{p}<0.05$ were considered to be significant.

\section{Results}

Telomere shortening in primary cultured cells. As shown in Fig. 1A, all NNEE cells (10-13 metaphases each from the 8 patients) had normal chromosome morphology; the chromosomal count of the metaphases was 46 (Fig. 1B). In the ESCC cells, the chromosomal counts of the metaphases were 68 (12 metaphases from patient E9Ca), and 67 and/or 68 (11 metaphases from patient E10Ca). The mean telomere lengths of chromosomes in the ESCC cells were significantly less $(p<0.0001)$ than those in the corresponding NNEE of the same patient. The telomere lengths of seven of the NNEE cells, excluding E7N, showed marked homogeneity: very short telomeres were generally observed in the NNEE cells (Table I), and the standard deviations were very small. In the E7N metaphases (Fig. 1C), the telomere lengths of 5p, 11p, $6 q$, and $12 q$ were significantly greater than the mean telomere length, whereas the telomere lengths of $9 p, 13 p, 17 p, 19 p$, $21 \mathrm{p}, 22 \mathrm{p}, 3 \mathrm{q}, 17 \mathrm{q}$, and $22 \mathrm{q}$ were significantly less than the mean telomere length. In the E8N metaphases (Fig. 1D), the telomere length of $13 q$ was significantly greater than the mean telomere length, and the telomere lengths of $21 \mathrm{p}$ and $8 \mathrm{q}$ were significantly less than the mean telomere length. In the E12N metaphases (Fig. 1H), the telomere lengths of 14p and $\mathrm{Yq}$ were significantly less than the mean telomere length. In the E13N metaphases (Fig. 1I), the telomere length of $4 \mathrm{p}$ was significantly greater than the mean telomere length, and the telomere length of $21 \mathrm{p}$ was significantly less than the mean telomere length. In the E14N metaphases (Fig. 1J), the telomere lengths of $22 \mathrm{p}$ and $\mathrm{Yq}$ were significantly less than the mean telomere length. In the eight NNEE cells combined, no common or specific chromosome in the p- or q-arms had significantly shorter telomeres than the other chromosomes (Fig. 1C-J).

Southern blot analysis. As shown in Fig. 2, the mean telomere lengths in the NNEE cells examined by Southern blotting were significantly less than those of normal esophageal tissues obtained at autopsy. The telomeres of both groups of cells did not shorten with age (range 40-75 years). 

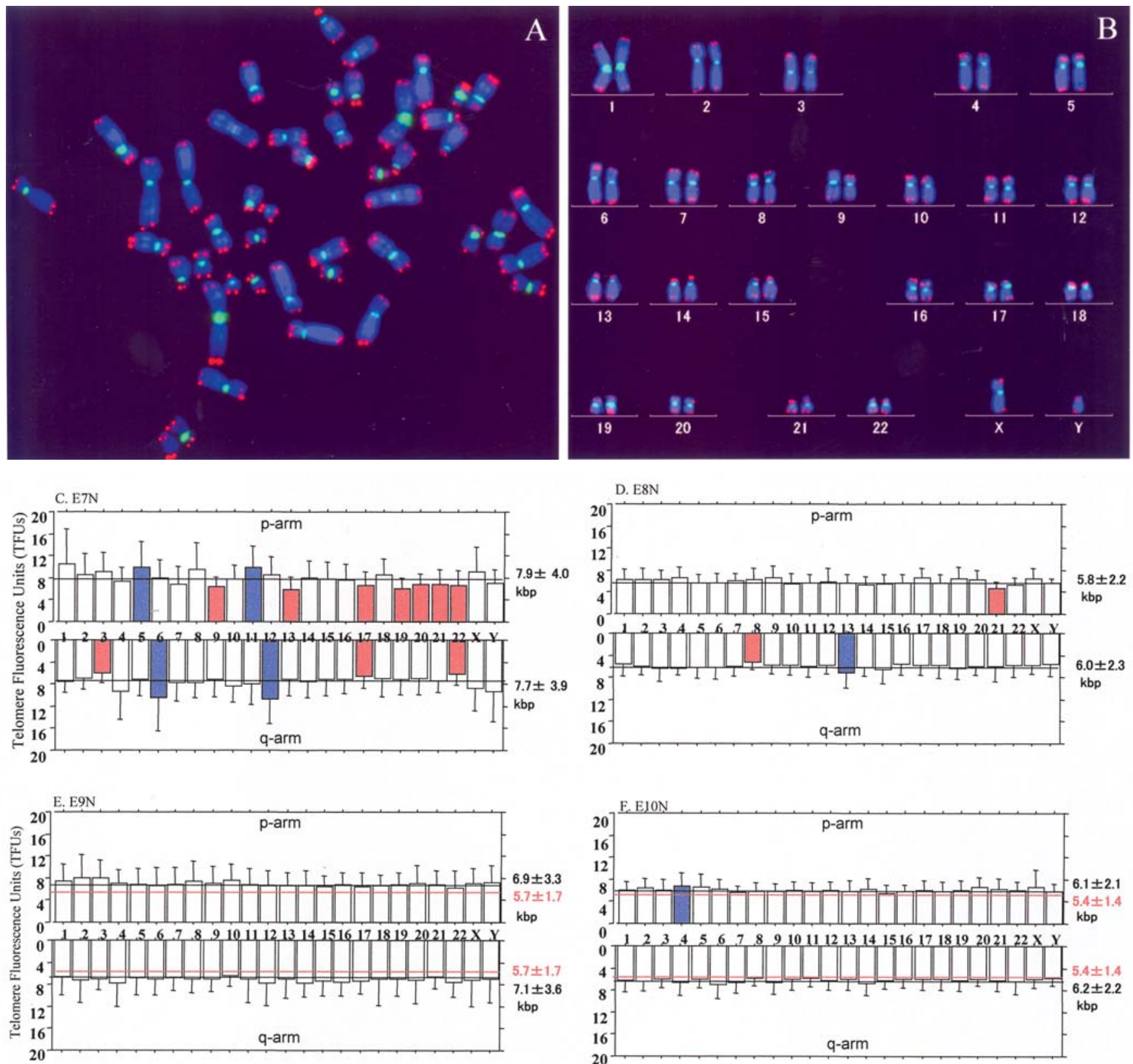

Immunohistochemical staining. The hTERT protein was strongly expressed in the nuclei and cytoplasm of almost all of the basal cells, a few of the epibasal cells, and almost all of the lymphocytes in the stromal tissue (Fig. 3).

Chromosomal aneuploidy of ESCC and karyotype of NNEE; gain and loss. We examined specific chromosomal abnormalities by observing metaphase spreads using color FISH with subtelomere-specific probes. We observed both ESCC (E9Ca and E10Ca) and adjacent NNEE cells (E9N and E10N) (data not shown). The specific subtelomeres 3q, 8q, $9 \mathrm{q}, 11 \mathrm{p}, 11 \mathrm{q}, 12 \mathrm{q}, 17 \mathrm{p}$, and 18q in both ESCC (E9Ca and E10Ca) cells showed an increased gain of aneuploidy in comparison with the NNEE cells (E9N and E10N). We found distinctly increasing chromosomal instability in the ESCC cells compared with the adjacent NNEE cells (data not shown). However, we did not establish any correlation between telomere shortening or gain of specific chromosomes in either of the chromosomal arms.

Anaphase/telophase bridge analysis. We determined the correlation of telomere length with the number of anaphase/ telophase bridges in ESCC and NNEE cells. Although anaphase/telophase bridges were observed in both ESCC and NNEE cells (Fig. 4A and B), their frequency was significantly dependent on telomere shortening in both cell types $(\mathrm{p}=0.0231)($ Fig. 4C).

\section{Discussion}

Functional telomeres protect the chromosome ends from recombination and fusion and are therefore essential for maintaining chromosomal stability (20-23). In the presence of shortened telomere repeat fragments, the ends of linear chromosomes may undergo bridge-fusion breakage events that result in both structural and numerical chromosomal abnormalities $(21,24,25)$. Therefore, genetically unbalanced chromosomal translocations, a key feature of most human cancers, are closely associated with the presence of shortened telomeres. 

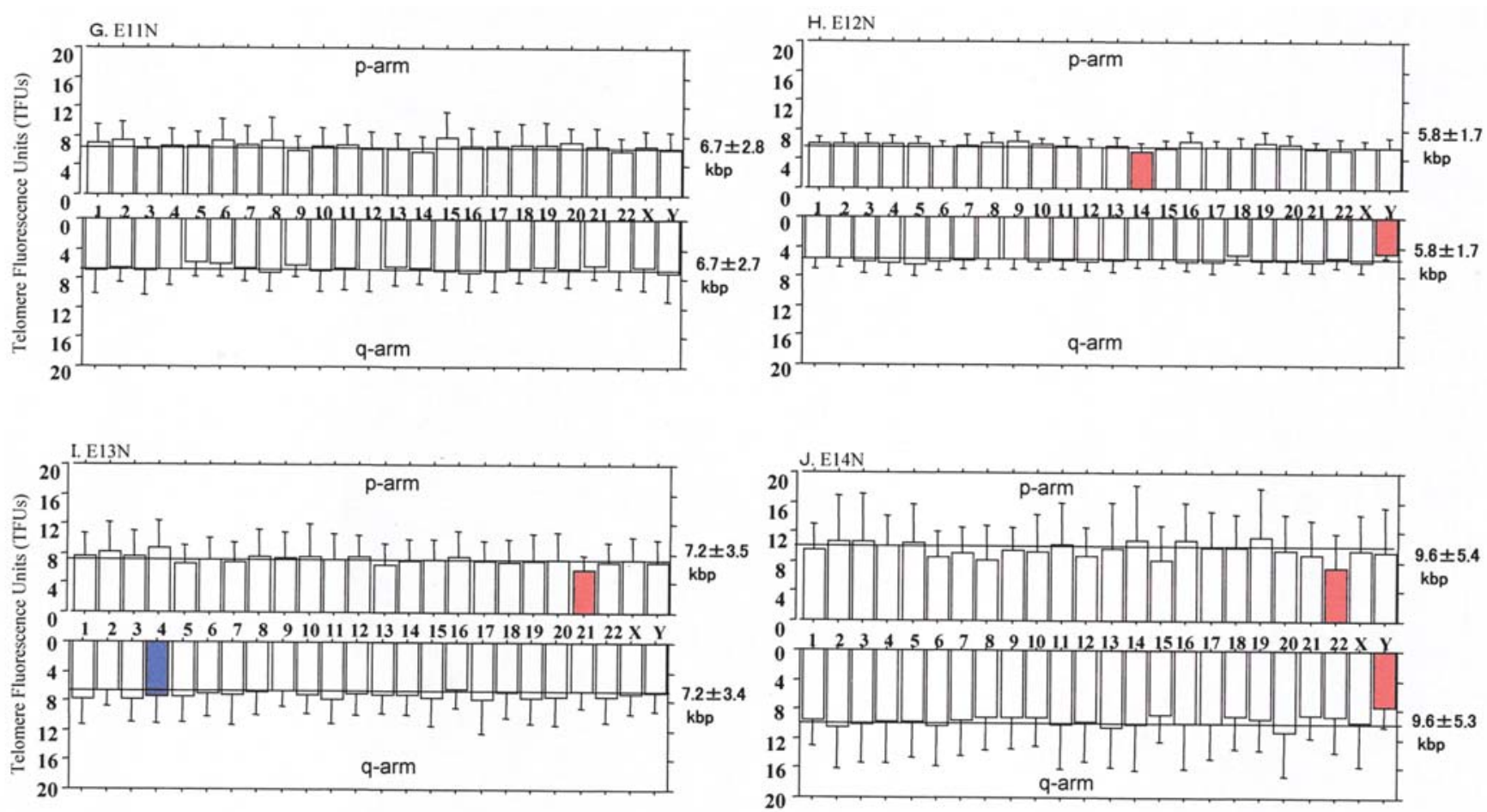

Figure 1. Examples of quantitative fluorescence in situ hybridization (Q-FISH) using normal and cancerous esophageal cells and a PNA telomeric probe, a PNA centromeric probe, and DAPI counterstain. Q-FISH revealed variations in the telomere lengths of each chromosome in NNEE cells. Bar plots show a comparison of the average telomere lengths in the p- and q-arms of individual chromosomes with the mean telomere length of the 8 NNEE cell lines. (A) Specificity of telomeric (red) and centromeric (green) signals during metaphase (stimulated) in a cell derived from non-cancerous esophageal epithelium (NNEE). (B) Q-FISH karyotype analysis of metaphase cells in a cell derived from NNEE. (C) E7N, (D) E8N, (E) E9N, (F) E10N (G) E11N, (H) E12N, (I) E13N, and (J) E14N cells. The blue bar indicates a significantly greater telomere length than the mean, and the red bar a significantly shorter telomere length than the mean. These plots compared the average telomere length in the p- and q-arms of chromosomes from NNEE cells (black line), ESCC cells (red line), and the telomere lengths in the p- and q-arms of individual chromosomes from NNEE cells. The telomere lengths of the seven NNEE cells showed marked homogeneity excluding E7N. The mean telomere lengths of chromosomes in the ESCC cells were significantly less than those in the corresponding NNEE cells. There was no specific chromosome with a p- or q-arm that had shorter telomeres in any of the cells from the eight NNEE samples.

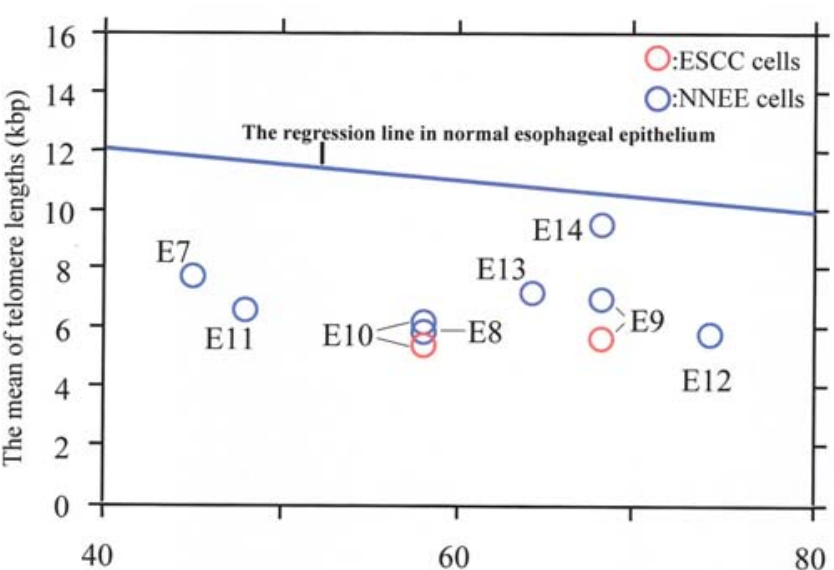

Age (years old)

Figure 2. Comparisons of telomere lengths of NNEE cells and normal esophageal epithelium by Southern blotting. The telomere lengths in ESCC and NNEE cells were significantly less than those of normal esophageal epithelium tissue obtained at autopsy from individuals age-matched with the samples used for Southern blotting $(\mathrm{p}<0.001)$.

In this study, we measured telomere length in the arms of specific chromosomes from cell cultures derived from ESCC and nearby NNEE tissue. Most of the median TFUs in the pand q-arms of chromosomes in ESCC cells were significantly shorter than the median TFUs in the corresponding p- and qarms in NNEE cells. Martens et al reported that telomeres on chromosome $17 \mathrm{p}$ in cancer cells were shorter than the telomeres in normal cells and that these relatively short telomeres contributed to the frequent loss of $17 \mathrm{p}$ alleles seen in human cancer (26). For certain patients in our study, we observed that specific chromosomes had either significantly shorter or longer telomeres than the median TFUs, whereas the same phenomenon was not observed in other patients. Thus, it is unlikely that telomere shortening of a particular chromosome is responsible for the cancer. It is likely that the overall shortening of telomeres in NNEE cells leads to carcinogenesis in ESCC cells (27).

Mandard et al reported that ESCC in the esophagus was consistent with field cancerization and correlated with mutant p53 (28). We investigated telomere lengths in NNEE and ESCC cells by Southern blotting and discovered that telomeres were significantly shorter than those of normal esophageal tissues obtained at autopsy. This alternative method of telomere length measurement further justifies the contention that telomere shortening occurs not only in ESCC but also in the nearby NNEE. These results suggest that telomere shortening in the esophageal epithelium is linked to carcinogenesis in ESCC and field cancerization in the esophagus.

On the other hand, the hTERT protein, detected by IHC, was strongly expressed in the nuclei and cytoplasm of almost 

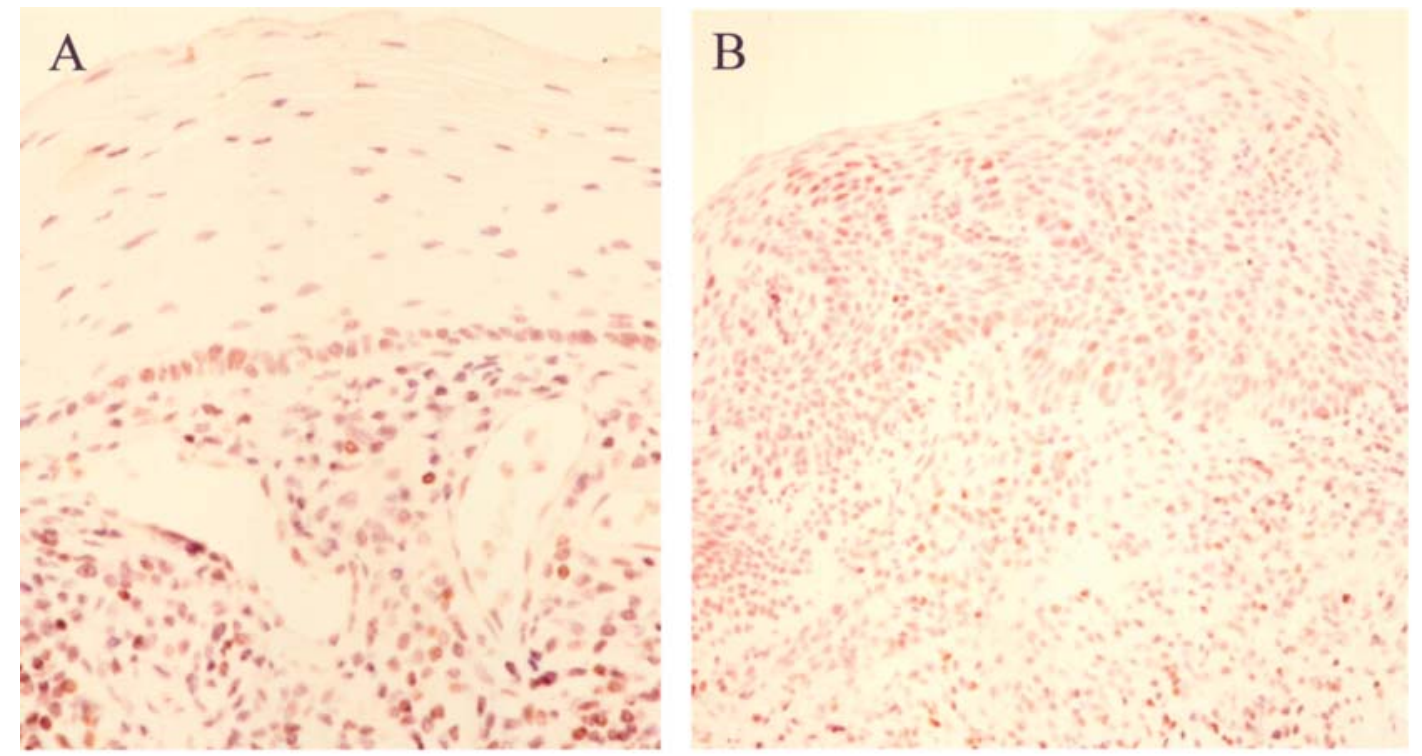

Figure 3. Immunohistochemical (IHC) staining of normal esophageal epithelium and cancer in tissue sections. (A) IHC shows that the hTERT protein is expressed in the basal cells in normal esophageal epithelium and in lymphocytes in normal esophageal submucosa. (B) IHC shows that the hTERT protein is expressed in the cancer cells in cancer areas and in lymphocytes in normal esophageal submucosa.

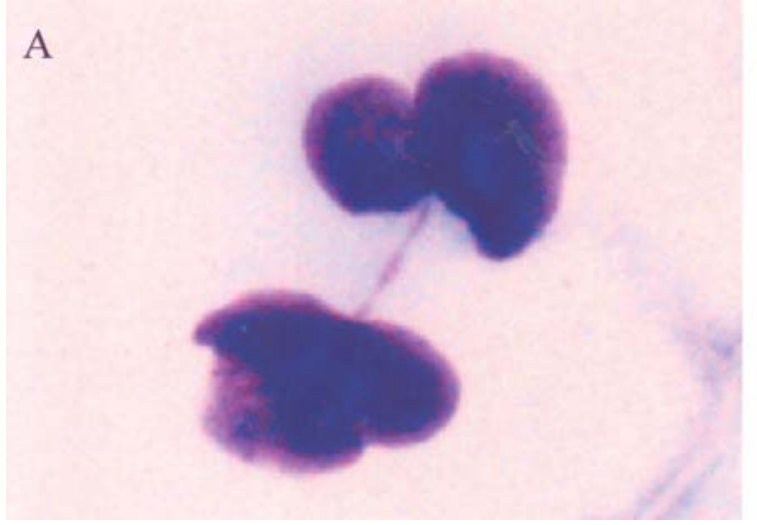

C

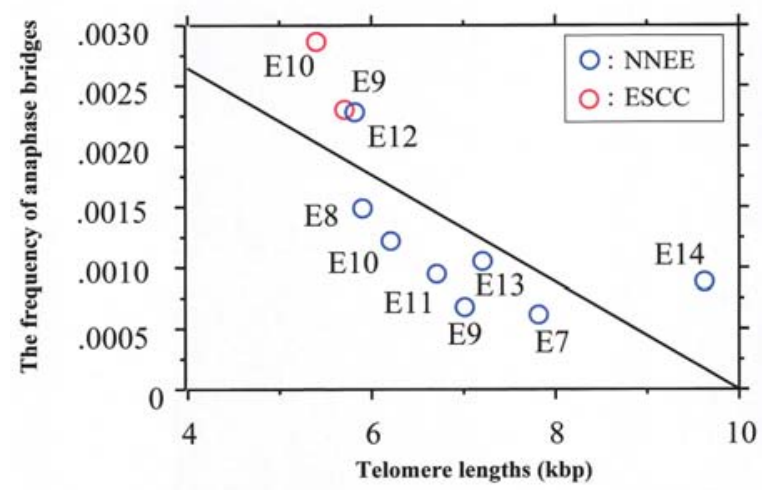

The frequency of anaphase bridges $=0.00441-.00044 * \mathrm{TRF} ; \mathrm{R}^{\wedge} 2=.508$ $\mathrm{r}=-0.696, \mathrm{p}=0.0231$

Figure 4. Anaphase/telophase bridge analysis. (A) Cancer cells (E9Ca). Images show a chromatin string connecting nuclei in two adjacent cells, connecting two lobes of a nucleus, and connecting two nuclei. (B) Epithelial cells (E9N). Image shows a chromatin string connecting two lobes of a nucleus. (C) Correlation of telomere lengths and anaphase/telophase bridges in ESCC and NNEE. The frequency of anaphase/telophase bridges showed a significant inverse correlation with telomere length in ESCC and NNEE $(\mathrm{p}=0.0231)$

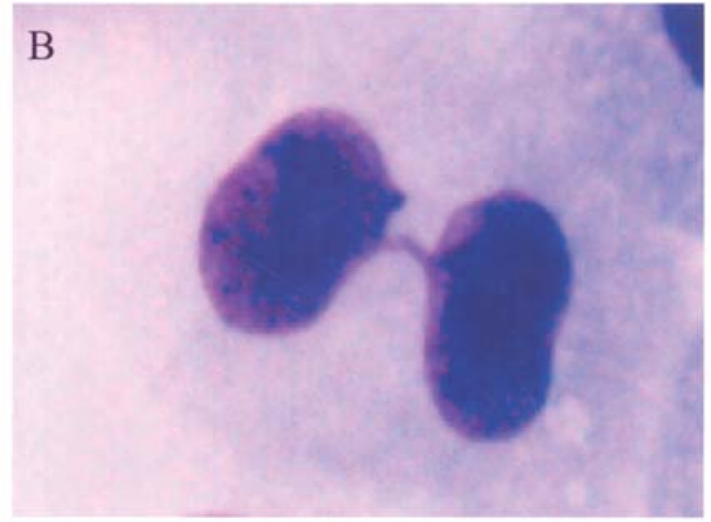

all of the basal cells, a few of the parabasal cells in NNEE, and in the nuclei and cytoplasm of almost all ESCCs. These results suggested that these normal cells have hTERT expression, and might also explain why ESCC arises from NNEE by field cancerization. Both the presence and relative abundance of these hTERT-expressing epithelial cells within NNEE thus lead us to speculate that ESCC may arise from these hTERT-expressing epithelial cells.

Anaphase/telophase bridges are a hallmark of telomere dysfunction and can lead to chromosomal losses, gains, and rearrangements after breakage $(3,29)$. Although NNEE cells had anaphase/telophase bridges, the frequency of anaphase bridges in ESCC cells was significantly higher than in NNEE cells. We did not find aneuploidy in the 8 samples of NNEE cells, and only 2 of the ESCC samples showed aneuploidy. The frequency of anaphase/telophase bridges was significantly dependent on telomere shortening in ESCC and NNEE. These results also suggest that telomere shortening-related chromosomal instability is likely to accelerate carcinogenesis in the esophagus.

In conclusion, very short telomeres and anaphase/ telophase bridges were found in both ESCC and NNEE cells using a number of different measurement techniques. This 
suggests that genetically unbalanced chromosomal translocations and anaphase/telophase bridges are a result of shortened telomeres in the cells, and that carcinogenesis in ESCC cells may propagate from NNEE cells. This study furthers our understanding of the phenomenon by which telomere shortening and chromosomal instability possibly lead to carcinogenesis and field cancerization in the esophagus.

\section{Acknowledgements}

This study was supported in part by Grants-in-Aid for Scientific Research (C18591432, Hoga18659364) from the Ministry of Education, Culture, Sports, Science and Technology of Japan, and from the Research Fund of Mitsukoshi Health and Welfare Foundation 2006, Japan. The authors wish to thank S. Nishimura for her expert technical assistance and Dr H. Kondo for the helpful assistance with the cell culture.

\section{References}

1. Autexier $\mathrm{C}$ and Greider $\mathrm{CW}$ : Telomerase and cancer: revisiting the telomere hypothesis. Trends Biochem Sci 21: 387-391, 1996.

2. Artandi SE, Chang S, Lee SL, Alson S, Gottlieb GJ, Chin L and DePinho RA: Telomere dysfunction promotes non-reciprocal translocations and epithelial cancers in mice. Nature 406: 641-645, 2000

3. Gisselesson D, Jonson T, Petersen A, Strombeck B, Dal Cin P, Hoglund M, Mitelman F, Mertens F and Mandahl N: Telomere dysfunction triggers extensive DNA fragmentation and evolution of complex chromosome abnormalities in human malignant tumors. Proc Natl Acad Sci USA 98: 12683-12688, 2001.

4. Blasco MA: Telomerase beyond telomeres. Nat Rev Cancer 2: 627-633, 2002

5. Hackett JA and Greider CW: Balancing instability: dual roles for telomerase and telomere dysfunction in tumorigenesis. Oncogene 21: 619-626, 2002.

6. Harley CB and Villeponteau B: Telomeres and telomerase in aging and cancer. Curr Opin Genet Dev 5: 249-255, 1995.

7. Shay JW: Aging and cancer: are telomeres and telomerase the connection? Mol Med Today 1: 378-384, 1995.

8. de Lange T: Telomeres and senescence: ending the debate. Science 279: 334-335, 1998.

9. Greider CW: Telomeres and senescence: the history, the experiment, the future. Curr Biol 8: R178-R181, 1998.

10. DePinho RA. The age of cancer. Nature 408: 248-254, 2000.

11. Takubo K, Nakamura KI, Izumiyama N, Sawabe M, Arai T, Esaki Y, Tnaka Y, Mafune K, Fujiwara M, Kammori M and Sasajima K: Telomere shortening with aging in human esophageal mucosa. Age 22: 95-99, 1999.

12. Hamilton SR and Aaltonen L: World Health Organization Classification of Tumours, Tumours of the Digestive System, Pathology and Genetics. IARC Press, Lyon, pp17-19, 2000.

13. Nielsen PE, Egholm M, Berg RH and Buchardt O: Sequenceselective recognition of DNA by strand displacement with a thymine-substituted polyamide. Science 254: 1497-1500, 1991.
14. Egholm M, Buchardt O, Christensen L, Behrens C, Freier SM, Driver DA, Berg RH, Kim SK, Nord B and Nielsen PE: PNA hybridizes to complementary oligonucleotides obeying the Watson-Crick hydrogen-bonding rules. Nature 365: 566-568, 1993.

15. Lansdorp PM, Verwoerd NP, van de Rijke FM, Dragowska V, Little MT, Dirks RW, Raap AK and Tanke HJ: Heterogeneity in telomere length of human chromosomes. Hum Mol Genet 5: 685-691, 1996.

16. Enomoto T, Sugawa H, Inoue D, Miyamoto M, Kosugi S, Takahashi T, Kitamura N, Yamamoto I, Konishi J and Mori T: Establishment of a human undifferentiated thyroid cancer cell line producing several growth factors and cytokines. Cancer 65 : 1971-1979, 1990

17. Kammori M, Onoda N, Nakamura K, Izumiyama N, Ogisawa K, Kurabayashi R, Ogawa T, Kaminishi M, Poon SSS and Takubo $\mathrm{K}$ : Specific subtelomere loss on chromosome der(11)t( $3 ; 11)$ (q23;q23)x2 in anaplastic thyroid cancer cell line OCUT-1. Int J Mol Med 18: 9-16, 2006.

18. Bosch M, Rajmil O, Martinez-Pasarell O, Egozcue J and Templado C: Linear increase of diploidy in human sperm with age: a four-colour FISH study. Eur J Hum Genet 9: 533-538, 2001.

19. Kammori M, Izumiyama N, Hashimoto M, Nakamura K, Okano T, Kurabayashi R, Hiki N, Honma N, Ogawa T, Kaminishi M and Takubo K: Expression of human telomerase reverse transcriptase (hTERT) gene and protein, and of estrogen and progesterone receptors, in breast tumors: Preliminary data from neo-adjuvant chemotherapy. Int J Oncol 27: 1257-1264, 2005.

20. Chin L, Artandi SE, Shen Q, Tam A, Lee SL, Gottlieb GJ, Greider CW and DePinho RA: p53 deficiency rescues the adverse effects of telomere loss and cooperates with telomere dysfunction to accelerate carcinogenesis. Cell 97: 523-527, 1999.

21. Artandi SE and DePinho RA: A critical role for telomeres in suppressing and facilitating carcinogenesis. Curr Opin Genet Dev 10: 39-46, 2000.

22. Rudolph KL, Millard M, Bosenberg MW and DePinho RA: Telomere dysfunction and evolution of intestinal carcinoma in mice and humans. Nat Genet 28: 155-159, 2001.

23. van Heek NT, Meeker AK, Kern SE, Yeo CJ, Lillemoe KD, Cameron JL, Offerhaus GJ, Hicks JL, Wilentz RE, Goggins MG, de Marzo AM, Hruban RH and Maitra A: Telomere shortening is nearly universal in pancreatic intraepithelial neoplasia. Am J Pathol 161: 1541-1547, 2002.

24. McClintock B: The stability of broken ends of chromosomes in Zea mays. Genetics 26: 234-282, 1941.

25. O'Hagan RC, Chang S, Maser RS, Mohan R, Artandi SE, Chin L and DePinho RA: Telomere dysfunction provokes regional amplification and deletion in cancer genomes. Cancer Cell 2: 149-155, 2002.

26. Martens UM, Zijlmans JM, Poon SS, Dragowska W, Yui J, Chavez EA, Ward RK and Lansdorp PM: Short telomeres on human chromosome 17p. Nat Genet 18: 76-80, 1998.

27. Braakhuis BJM, Tabor MP, Kummer JA, Leemans CR and Brakenhoff RH: A genetic explanation of Slaughter's concept of field cancerization: evidence and clinical implications. Cancer Res 63: 1727-1730, 2003

28. Mandard AM, Hainaut P and Hollstein M: Genetic steps in the development of squamous cell carcinoma of the esophagus. Mutation Res 462: 335-342, 2000

29. O'Sullivan JN, Bronner MP, Brentnall TA, Finley JC, Shen WT, Emerson S, Emond MJ, Gollahon KA, Moskovitz AH, Crispin DA, Potter JD and Rabinovitch PS: Chromosomal instability in ulcerative colitis is related to telomere shortening. Nat Genet 32: 280-284, 2002. 